\title{
Category effects in visual search: A failure to replicate the "oh-zero" phenomenon
}

\author{
JOHN DUNCAN \\ MRC Applied Psychology Unit, Cambridge, England
}

\begin{abstract}
In the experiment of Jonides and Gleitman (1972), subjects searched displays of digits or letters for single, specified digit or letter targets. The slope of the function relating reaction time to display size was positive (mean $=25 \mathrm{msec} / \mathrm{item}$ ) if target and nontargets belonged to the same alphanumeric category (within-category search), but zero if target and nontargets belonged to different categories (between-category search). This held even for the target 0 , whose categorical relationship to nontargets was determined entirely by the name it was given. In the present paper, two attempted replications are reported, one as close as practically possible. For the unambiguous targets A, Z, 2, and 4, slopes were greater in within-category search than in betweencategory search, but positive and very variable in both cases. For the ambiguous target 0 , slopes were identical in within-category and between-category search, and again positive. The results suggest that with single, specified targets, differences between within-category and between-category search may be due entirely to variation in the average physical resemblance between target and nontargets. In line with previous findings, they show that one cannot characterize within-category search as generally "serial" and between-category search as generally "parallel."
\end{abstract}

Performance in visual search is strongly influenced by the categorical relationship between targets and nontargets. With displays of alphanumeric characters, letter targets are more easily found when nontargets are digits (between-category search) than when they are letters (within-category search), whereas digit targets - re more easily found when nontargets are letters ( $\mathrm{v}$ veen-category search) than when they are digits (within-category search). This widely reported "category effect" in visual search (e.g., Brand, 1971; Gleitman \& Jonides, 1976, 1978; Ingling, 1972; Jonides \& Gleitman, 1972, 1976) is the subject of the present paper.

It is important to distinguish two cases. In the first, the size of the target set (i.e., the number of different characters specified as potential targets on a single trial) is greater than one, here termed $T>1$. For this case, the advantage of between-category search has been widely reported (e.g., Gleitman \& Jonides, 1976, 1978; Jonides \& Gleitman, 1976), and is easily explained. In within-category search, the target set for a single trial might consist (for example) of the digits 2,7 , while nontargets are drawn from the set 3 , $4,6,8,9$. To decide whether or not a target is present, each character in the display must be classified into one of these two sets, a classification which is novel to the experiment and certainly ill-learned. In between-category search, on the other hand, the tar-

The author's mailing address is: MRC Applied Psychology Unit, 15 Chaucer Road, Cambridge CB2 2EF, England. get set for a single trial might consist of the letters $L$, $Z$, with nontargets again drawn from the set $3,4,6$, 8,9 . To decide whether or not a target is present, it is now necessary only to classify each character in the display as letter or digit. This is a well-learned classification, and on these grounds will surely be more efficient than its ill-learned within-category counterpart. Effects of the familiarity of the classification distinguishing targets from nontargets have been shown by Neisser (1963) and Shiffrin and Schneider (1977), and are frequently addressed in terms of the increased "automaticity" of well-learned operations (e.g., Duncan, 1980; Schneider \& Shiffrin, 1977).

In the second case, only a single target is specified on each trial $(T=1)$. Again, the category effect has been widely reported (e.g., Brand, 1971; Ingling, 1972; Jonides \& Gleitman, 1972). How is it to be explained?

An explanation in terms of practice or "automaticity" is unappealing, because even the withincategory case now calls for no ill-learned classifications. The target, for example, might be the digit 2 , while nontargets are other digits. On the face of it, deciding for each displayed character whether or not it is a 2 would seem very well learned, perhaps at least as well learned as deciding whether or not it is a digit.

One possibility concerns the strong influence, in visual search, of the physical resemblance between targets and nontargets. Not surprisingly, targets are more easily found among physically dissimilar than among similar nontargets (Neisser, 1963). The category effect obtaining with $T=1$ could be explained 
if, in general, it were true that digits are physically more similar to other digits than to letters, and vice versa.

Strong evidence against this explanation was provided by Jonides and Gleitman (1972). Their experiment will be described in some detail. On each trial, a single target was named. For half the subjects, this target was drawn (at random on each trial) from the set $\mathrm{A}, \mathrm{Z}, \mathrm{O}$ (called "oh"). For the remaining subjects the target was drawn from the set 2, 4, $O$ (physically identical to the "oh", but here called "zero"). A display of two, four, or six characters was then shown, and as fast as possible the subject indicated whether or not the named target was present. At most, one target was present in the display; remaining characters were nontargets. The category of nontarget characters was also varied between subjects, orthogonally to the variation of target category. Thus, for half of those subjects whose targets were letters, nontargets were also letters (drawn from the set C, E, F, H, I, J, $K, L, N, P, R, S, T, U, V, X, Y$ ), producing withincategory search. For the remaining subjects whose targets were letters, nontargets were digits (drawn from the set $1,3,5,6,8,9$ ), producing betweencategory search. Similarly, for half the subjects whose targets were digits, nontargets were also digits (within-category search), whereas for half they were letters (between-category search).

The crucial data concern trials on which the ambiguous target $\mathrm{O}$, called "oh" for half the subjects and "zero" for the other half, was specified. For these trials, functions of reaction time (RT) against display size had quite steep slopes (mean $=24.0 \mathrm{msec}$ / item) in within-category search, but were essentially flat (mean $=-2.4 \mathrm{msec} / \mathrm{item}$ ) in between-category search. This effect could not have been due to variations in the physical resemblance between target and nontargets, since when $\mathrm{O}$ was sought, for example, in a background of letters, only the name it was given, "oh" or "zero," determined whether search was within-category or between-category, displays in the two cases being identical. These data suggest a strong category effect in visual search, obtaining even when $T=1$ and when physical resemblance between target and nontargets is controlled.

In fact, the results for trials with the ambiguous target $O$ were almost identical to those for trials on which one of the unambiguous targets, $\mathrm{A}$ or $\mathrm{Z}$ for half the subjects and 2 or 4 for the other half, was specified. For these latter trials, mean slopes were 25.9 and $1.3 \mathrm{msec} / \mathrm{item}$, respectively, for withincategory and between-category search.

In addition to suggesting that the category effect with $T=1$ is not due to variations in physical resemblance between target and nontargets, the Jonides and Gleitman (1972) data are sometimes taken to support a stronger position. It is sometimes suggested that a slope of close to zero is characteristic of between-category search and suggests parallel processing, while a much steeper slope is characteristic of within-category search and suggests serial processing. For two reasons, however, this stronger position should be seriously doubted. The first reason for doubt is empirical. Though several studies have found a category effect with $T=1$, between studies there is substantial variation in absolute slopes in both between-category and within-category cases, so that, across studies, the two cases show substantial overlap in slopes (e.g., Corcoran \& Jackson, 1977; Egeth, Atkinson, Gilmore, \& Marcus, 1973; Taylor, 1978). The second reason for doubt is theoretical. For a variety of reasons, even parallel models usually predict some positive slope, unspecified in absolute size (e.g., Duncan, 1980; Eriksen \& Spencer, 1969). Thus, absolute slopes cannot show whether processing is parallel or serial. These two considerations together make it unwise to conclude that betweencategory search gives generally flat, "parallel" functions and within-category search gives generally steep, "serial" functions.

The present paper reports two attempted replications of Jonides and Gleitman's (1972) results. Experiment 1 was motivated by the following idea. In the within-category condition of the Jonides and Gleitman (1972) experiment, changes in target from trial to trial must have necessitated corresponding changes in set. But in between-category search, if decisions were based on category rather than identity, it could have been immaterial that target identity changed from trial to trial, since target category remained fixed. The present Experiment 1 was planned to test the importance of this difference. For some subjects the target changed from trial to trial, while for others it was fixed for a block of trials. As it turned out, this manipulation had no major effect on the pattern of results. More importantly, however, results were at variance in several respects with the original results of Jonides and Gleitman (1972). Accordingly, Experiment 2 was run as an exact replication of the original Jonides and Gleitman (1972) study.

\section{EXPERIMENT 1}

\section{Method}

Sabjects. Twenty-four subjects between the ages of 18 and 40 years (mean $=32.2$ years) were recruited from the paid subject panel of the Applied Psychology Unit. Two were male.

Task. The experiment was run on-line on a Cambridge Electronic Design (CED) computer system. Displays were presented on a cathode ray tube coated with P31 phosphor. The subject sat alone in a semidarkened room, viewing the display from a fixed headrest.

Displays were made up of digits and uppercase letters from the standard CED character set, each constructed within a 7 (vertical) 
$\times 5$ (horizontal) dot matrix. With the sole exception of the thinner characters 1 and $I$, each character subtended a visual angle of $.43 \mathrm{deg}$ (vertical) $\times .27 \mathrm{deg}$ (horizontal) at the viewing distance of approximately $45 \mathrm{~cm}$.

Each trial began with the presentation of a single target character in the center of the screen. This remained until the subject pressed a footswitch, initiating a 1,600 -msec blank interval. At the end of this time, a central fixation point appeared for $400 \mathrm{msec}$, followed at once by the stimulus display. This display contained 2 , 4 , or 6 characters, all different, arranged on the perimeter of an imaginary circle that was $3.4 \mathrm{deg}$ in diameter (measuring between the centers of diametrically opposite characters), centered on fixation. The previously displayed target was present in exactly half the displays. All subjects pressed a key with the left index finger if the target was present and with the right index finger if the target was absent. The response caused the display to vanish, and began a 2-sec blank interval preceding the next trial.

There were 12 possible positions for stimulus characters, corresponding to the 12 clock positions on the 3.4-deg circle. Positions for the characters to be displayed were chosen afresh on each trial, randomly except for the following constraints. The positions may be regarded as grouped into 6 pairs: A (12 and $10^{\prime}$ clock), B (2 and 3 o'clock), C (4 and 5 o'clock), D (6 and 7 o'clock), E (8 and 9 $o^{\prime}$ clock), and F (10 and $11 o^{\prime}$ 'clock). There were never characters in both positions of a pair. Each display contained at least two diametrically opposite characters, regarding any character in pair $A$ as diametrically opposite to any character in pair $\mathrm{D}$, and so on.

Although the present task was based on that of Jonides and Gleitman (1972), in detail there were several differences between the two, resulting in part from the use of different apparatus (on-line control vs. use of a tachistoscope). Notable differences concerned the manner of initial target presentation (auditory in the Jonides and Gleitman study), the timing of stimulus displays (the displays of Jonides and Gleitman were presented $400 \mathrm{msec}$ after the subject depressed a footswitch, and were exposed for only $150 \mathrm{msec}$ ), the responses required (Jonides and Gleitman used separate groups of subjects to respond to target-present and targetabsent displays), and the timing of intertrial intervals (Jonides and Gleitman give a figure of approximately $10 \mathrm{sec}$ ). The size and structure of the stimulus displays, however, were closely similar in the two studies.

Design. For half the subjects, targets were always drawn from the set A, Z, O (called "oh"). For the other half, targets were always drawn from the set 2, 4, $O$ (called "zero"). For half the subjects, trial blocks were "mixed": as in the experiment of Jonides and Gleitman (1972), a new target was drawn at random on each trial from the subject's set of three possibilities. For the other subjects, trial blocks were "pure": the same target was used for all trials in a block. These two betweer-subjects factors were varied orthogonally, so that subjects were split at random into four equal groups.

Each subject served in a single session of approximately $11 / 2 \mathrm{~h}$. This session was split into two halves, one using digit nontargets (drawn at random on each trial from the set $1,3,5,6,8,9$ ) and the other using letter nontargets (drawn similarly from the set C, E, F, H, I, J, K, L, N, P, R, S, T, U, V, X, Y). Thus, the factor of within-category vs. between-category search was manipulated within subjects. The order of nontarget categories was counterbalanced across subjects, orthogonally to other factors.

Each half of the session had three blocks of trials, each block having a first subblock of 24 trials for warm-up (data not analyzed), followed, after a 10-sec pause, by the main subblock of 108 trials. For subjects whose blocks were mixed, the three blocks within one half of the session were essentially identical. For subjects whose blocks were pure, a different one of the subject's three targets was used in each block, and was fixed throughout the block (although it was always re-presented at the start of each trial). Orthogonally to the other factors, the order of targets across blocks was counterbalanced across subjects, but was the same for any one subject in each half of the session.

Within each subblock of 108 trials, the following factors were varied orthogonally: 3 (display sizes) $\times 2$ (target present vs. absent) $\times 6$ (target positions $A$ to $F$; a dummy variable for target absent displays) $\times 3$ (target identities; a dummy variable in pure blocks). With this constraint, trial sequences were separately randomized for each block and each subject.

Again, relationships to the Jonides and Gleitman (1972) study should be noted. They always used mixed blocks and varied nontarget as well as target category among subjects. Each subject served in only a single block of 18 practice plus 108 experimental trials. Target and nontarget characters were chosen from the same sets as those used in the present study.

A last important point should be emphasized. The "zero" of the CED character set was never used in the present study: instead, the "oh" was always used, both as the "oh" needed for half the subjects and as the "zero" needed for the others. However, this "oh," when called "zero," fit perfectly naturally with the remaining digits, in particular in having exactly the same height and width.

Instructions. Every effort was made to ensure that subjects categorized the stimuli as intended by the experimenter. The category of targets (letters vs. digits) was explicitly noted at the start of the session, and individual targets were introduced by name. Also explicitly noted at the start of the session was the category of the nontargets to be used first; the nontargets to be used second, however, were not mentioned until the first half of the session was complete.

The subjects were asked to respond as fast as possible without making mistakes.

\section{Results}

Trials immediately following errors were excluded from all analyses.

Reaction times. Data for the unambiguous targets A, Z, 2, and 4 are considered first. Functions of mean RT against display size for these targets are shown in Figure 1. There are four panels, one for each group of subjects. Each panel has functions for target-present and target-absent displays in withincategory and between-category search. Slopes and intercepts of best-fitting straight lines for these functions are shown in Table 1.

The most important results concern the comparison of within-category and between-category search. As expected, slopes were reduced in the betweencategory case, by an average of $14 \mathrm{msec} / \mathrm{item}$ for target-present displays and $21 \mathrm{msec} / \mathrm{item}$ for targetabsent displays (Table 1). In contrast to the results of Jonides and Gleitman (1972), however, the slopes were all positive and rather variable in both withincategory and between-category search.

The data were examined by analysis of variance, with block type (pure vs. mixed) and target category (digits vs. letters) as between-subjects factors and search type (within-category vs. between-category), target presence (present vs. absent), and display size $(2,4,6)$ as within-subject factors. The results described above were reflected in significant effects of search type $[F(1,20)=5.5, p<.05]$, display size $[\mathrm{F}(2,40)=86.5, \mathrm{p}<.001]$, and search type $\times$ display size $[F(2,40)=24.2, p<.001]$. Significant effects of target presence $[\mathrm{F}(1,20)=36.5, \mathrm{p}<.001]$ and target presence $\times$ display size $[\mathrm{F}(2,40)=22.1, \mathrm{p}<.001] \mathrm{re}$ - 

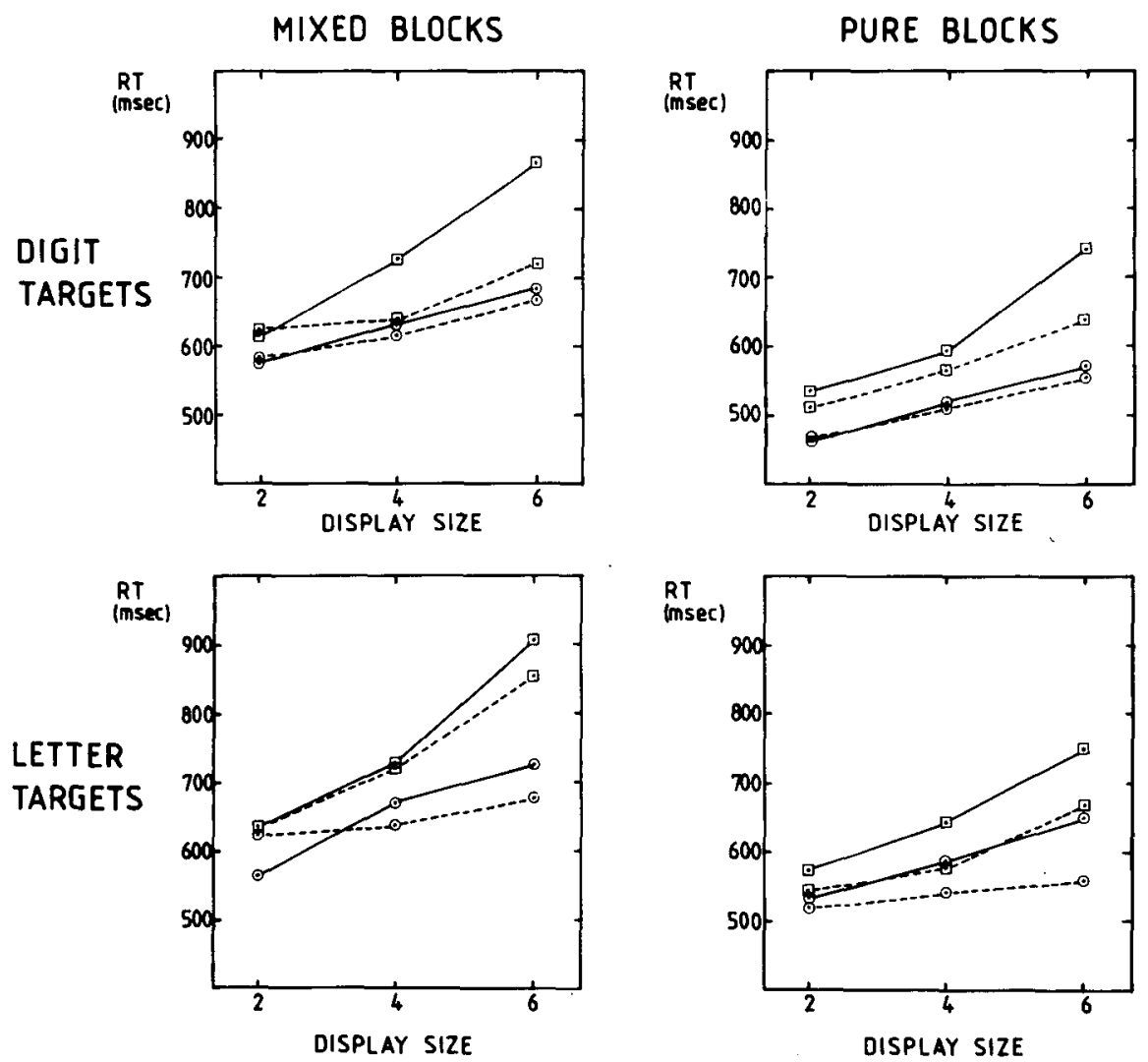

Figure 1. Experiment 1: Unambiguous targets. Functions of RT against display size. - -, withincategory search; ....., betweem-category search; $O$, target present; and $\square$, target absent.

flected the usual difference in slopes between targetpresent and target-absent displays. The interaction of search type $\times$ target presence was also significant $[F(1,20)=15.4, p<.001]$, showing that the difference between target-present and target-absent RTs was reduced in between-category search.

Turning to the between-subjects factors, block type was significant as a main effect $[F(1,20)=6.0$, $\mathrm{p}<.05$ ], indicating an overall advantage for pure blocks, but it showed no significant interactions. Target category appeared in only two significant interactions, target category $\times$ search type $\times$ target presence $[F(1,20)=7.5, p<.05]$ and target category $\times$ search type $\times$ target presence $\times$ display size $[F(2,40)=$

Table 1

Slopes (in Milliseconds/Item) and Intercepts (in Milliseconds) of Best-Fitting Straight Lines for Functions of RT Against Display Size for Unambiguous Targets in Experiment 1

\begin{tabular}{|c|c|c|c|c|c|}
\hline & & \multirow{2}{*}{\multicolumn{2}{|c|}{$\frac{\text { Within-Category Search }}{\text { Target }}$}} & \multirow{2}{*}{\multicolumn{2}{|c|}{$\frac{\text { Between-Category Search }}{\text { Target }}$}} \\
\hline & & & & & \\
\hline & & Present & Absent & Present & Absent \\
\hline & & \multicolumn{4}{|c|}{ Mixed Blocks } \\
\hline Digit Targets & $\begin{array}{l}\text { Slope } \\
\text { Intercept }\end{array}$ & $\begin{array}{r}27 \\
523\end{array}$ & $\begin{array}{r}63 \\
486\end{array}$ & $\begin{array}{r}22 \\
534\end{array}$ & $\begin{array}{r}25 \\
561\end{array}$ \\
\hline \multirow[t]{2}{*}{ Letter Targets } & $\begin{array}{l}\text { Slope } \\
\text { Intercept }\end{array}$ & $\begin{array}{r}41 \\
491\end{array}$ & $\begin{array}{r}68 \\
484\end{array}$ & $\begin{array}{r}13 \\
596\end{array}$ & $\begin{array}{r}55 \\
519\end{array}$ \\
\hline & & \multicolumn{4}{|c|}{ Pure Blocks } \\
\hline Digit Targets & $\begin{array}{l}\text { Slope } \\
\text { Intercept }\end{array}$ & $\begin{array}{r}27 \\
408\end{array}$ & $\begin{array}{r}52 \\
417\end{array}$ & $\begin{array}{r}23 \\
418\end{array}$ & $\begin{array}{r}32 \\
444\end{array}$ \\
\hline Letter Targets & $\begin{array}{l}\text { Slope } \\
\text { Intercept }\end{array}$ & $\begin{array}{r}29 \\
473\end{array}$ & $\begin{array}{r}44 \\
479\end{array}$ & $\begin{array}{r}10 \\
500\end{array}$ & $\begin{array}{r}31 \\
473\end{array}$ \\
\hline
\end{tabular}


MIXED BLOCKS
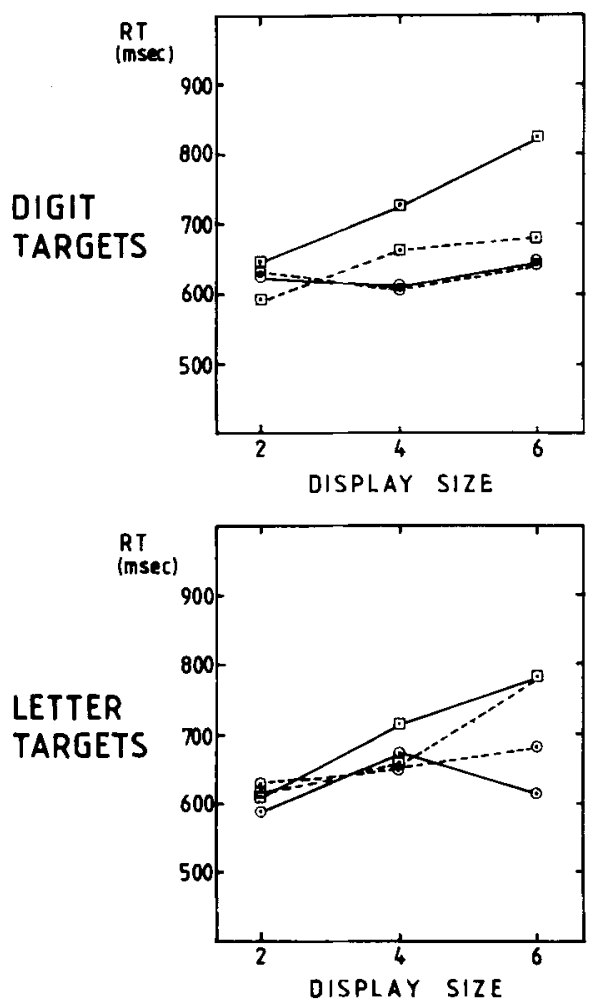

PURE BLOCKS
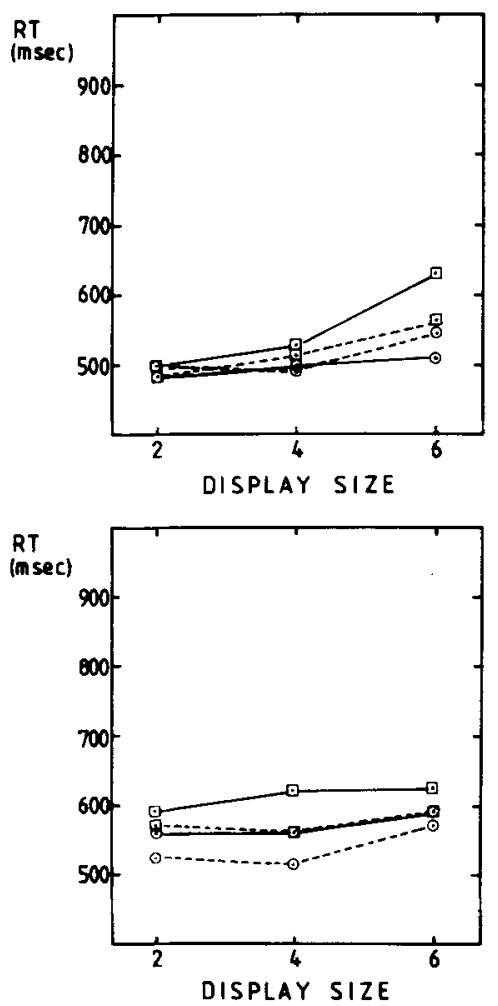

Figure 2. Experiment 1: Ambiguous targets. Functions of RT against display size. - - withincategory search; ....., between-category search; $O$, target present; and $\square$, target absent.

$5.7, p<.01]$. For digit targets, only target-absent displays showed reduced RTs and slopes in betweencategory search as compared with within-category search. For letter targets, both target-present and target-absent displays showed reduced RTs in the between-category case, but target-present displays showed the greater reduction in slopes. These minor variations in the overall pattern of results will not be discussed further.

Corresponding data for the ambiguous target $O$ are shown in Figure 2 and Table 2. Again, the most important results concern the comparison of withincategory and between-category search. In contrast to the result of Jonides and Gleitman (1972), there was

Table 2

Slopes (in Milliseconds/Item) and Intercepts (in Milliseconds) of Best-Fitting Straight Lines for Functions of RT Against Display. Size for Ambiguous Targets in Experiment 1

\begin{tabular}{|c|c|c|c|c|c|}
\hline & & \multirow{2}{*}{\multicolumn{2}{|c|}{$\frac{\text { Within-Category Search }}{\text { Target }}$}} & \multirow{2}{*}{\multicolumn{2}{|c|}{$\frac{\text { Between-Category Search }}{\text { Target }}$}} \\
\hline & & & & & \\
\hline & & Present & Absent & Present & Absent \\
\hline & & \multicolumn{4}{|c|}{ Mixed Blocks } \\
\hline Digit Targets & $\begin{array}{l}\text { Slope } \\
\text { Intercept }\end{array}$ & $\begin{array}{r}6 \\
604\end{array}$ & $\begin{array}{r}45 \\
553\end{array}$ & $\begin{array}{r}3 \\
617\end{array}$ & $\begin{array}{r}22 \\
555\end{array}$ \\
\hline \multirow[t]{2}{*}{ Letter Targets } & $\begin{array}{l}\text { Slope } \\
\text { Intercept }\end{array}$ & $\begin{array}{r}7 \\
596\end{array}$ & $\begin{array}{r}43 \\
531\end{array}$ & $\begin{array}{r}14 \\
599\end{array}$ & $\begin{array}{r}41 \\
522\end{array}$ \\
\hline & & \multicolumn{4}{|c|}{ Pure Blocks } \\
\hline Digit Targets & $\begin{array}{l}\text { Slope } \\
\text { Intercept }\end{array}$ & $\begin{array}{r}8 \\
467\end{array}$ & $\begin{array}{r}34 \\
417\end{array}$ & $\begin{array}{r}12 \\
462\end{array}$ & $\begin{array}{r}19 \\
444\end{array}$ \\
\hline Letter Targets & $\begin{array}{l}\text { Slope } \\
\text { Intercept }\end{array}$ & $\begin{array}{r}9 \\
538\end{array}$ & $\begin{array}{r}8 \\
581\end{array}$ & $\begin{array}{r}12 \\
491\end{array}$ & $\begin{array}{r}6 \\
554\end{array}$ \\
\hline
\end{tabular}


Table 3

Error Proportions in Experiment 1

\begin{tabular}{|c|c|c|c|c|c|c|}
\hline & \multicolumn{3}{|c|}{ Within-Category Search } & \multicolumn{3}{|c|}{ Between-Category Search } \\
\hline & \multicolumn{3}{|c|}{ Display Size (Characters) } & \multicolumn{3}{|c|}{ Display Size (Characters) } \\
\hline & 2 & 4 & 6 & 2 & 4 & 6 \\
\hline & \multicolumn{6}{|c|}{ Unambiguous Targets } \\
\hline \multirow[t]{2}{*}{ Target Absent } & $\begin{array}{l}.016 \\
.021\end{array}$ & $\begin{array}{l}.032 \\
.011\end{array}$ & $\begin{array}{l}.043 \\
.015\end{array}$ & $\begin{array}{l}.027 \\
.013\end{array}$ & $\begin{array}{l}.021 \\
.008\end{array}$ & $\begin{array}{l}.023 \\
.014\end{array}$ \\
\hline & \multicolumn{6}{|c|}{ Ambiguous Targets } \\
\hline $\begin{array}{l}\text { Target Present } \\
\text { Target Absent }\end{array}$ & $\begin{array}{l}.022 \\
.019\end{array}$ & $\begin{array}{l}.027 \\
.012\end{array}$ & $\begin{array}{l}.024 \\
.019\end{array}$ & $\begin{array}{l}.028 \\
.024\end{array}$ & $\begin{array}{l}.026 \\
.021\end{array}$ & $\begin{array}{l}.044 \\
.022\end{array}$ \\
\hline
\end{tabular}

no clear difference in slopes in the two cases. The mean reduction in slope in the between-category case was $-2.75 \mathrm{msec} /$ item for target-present displays and $10.5 \mathrm{msec} /$ item for target-absent displays (Table 2). Again, slopes were all positive and rather variable in both within-category and between-category search.

The data were examined by analysis of variance as before. Neither the main effect of search type $[F(1,20)$ $=1.8]$ nor the interaction of search type $\times$ display size $[F(2,40)=2.2]$ was significant. There was, however, a significant interaction of target category $x$ search type $X$ display size $[F(2,40)=3.9, p<.05]$. Any tendency for slopes to be less in the betweencategory case was confined entirely to the digit ("zero") targets. Otherwise, there were significant effects of display size $[F(2,40)=39.2, p<.001]$, target presence $[F(1,20)=14.8, p=.001]$, and target presence $x$ display size $[F(2,40)=11.6, p<.001]$, reflecting, as before, the usual difference in slopes between target-present and target-absent displays. Also significant were the interactions of search type $\times$ target presence $[F(1,20)=24.9, p<.001]$, block type $\times$ search type $\times$ target presence $[F(1,20)=5.5, p<$ $.05]$, and target category $\times$ search type $\times$ target presence $[F(1,20)=5.1, p<.05]$. The difference between target-present and target-absent RTs was smaller in between-category search than in withincategory search. This was especially so for mixed blocks and for digit targets. No explanation for this result is obvious.

The last significant effects were those of block type $[\mathrm{F}(1,20)=8.0, \mathrm{p}<.05]$, block type $\times$ display size $[F(2,40)=3.3, p<.05]$, and block type $\times$ target presence $x$ display size $[F(2,40)=4.9, p<.05]$. RTs were shorter in pure blocks than in mixed blocks, and in pure blocks slopes also were reduced, at least for target-absent displays.

The failure to find, for ambiguous targets, a significant difference in slopes between within-category and between-category search raises a question over the power of the experiment. In a further analysis of the data for ambiguous targets, best-fitting straight lines were fit to functions of RT against display size for each subject, and slopes entered into a two-way analysis of variance with search type and target presence as within-subjects factors. Collapsing across target presence, mean slopes were 19.4 and 15.6 $\mathrm{msec} / \mathrm{item}$, respectively, in within-category and between-category search. The standard error of each mean was $2.9 \mathrm{msec} / \mathrm{item}$. The difference in these means is $3.7 \mathrm{msec} / \mathrm{item}$, with a standard error of $3.1 \mathrm{msec} /$ item.

Errors. Mean error rates, averaged across betweensubjects variables, are shown in Table 3. Error rates were approximately stable across conditions.

\section{Discussion}

Nothing of interest resulted from comparing performance in pure and mixed blocks. This variable will not be discussed further.

In one respect, the results were similar to those of Jonides and Gleitman (1972). For unambiguous targets, slopes were greater in within-category search than in between-category search. In two other respects, however, the present results were different from those of the previous study.

The first difference concerns the ambiguous target $O$. For this target, there was no consistent difference in slopes between within-category and between-category search. The mean difference of about $4 \mathrm{msec} /$ item is negligible. Thus, in the present study, the difference in slopes between within-category and between-category search vanished when the physical resemblance between target and nontargets was controlled. These data are consistent with the view that, when $T=1$, the category effect in visual search is due entirely to uncontrolled variation in physical resemblance, unambiguous letters such as $\mathbf{A}$ and $\mathrm{Z}$ being on the average more similar to other letters than to digits, and unambiguous digits such as 2 and 4 being on the average more similar to other digits than to letters.

The second difference from the results of Jonides and Gleitman (1972) concerns absolute slopes. As noted before, although Jonides and Gleitman (1972) found slopes of essentially zero in between-category search, other studies have produced a range of positive slopes, with substantial overlap, across studies, 
in the slopes for between-category and withincategory cases. In the present experiment, too, slopes were positive and variable, with overlapping ranges for the two search types.

One possibility is that the present results were in some way influenced by the fact that the nontarget category was varied within subjects, perhaps disturbing the stability of subjects' strategies. To check on this, the results were reanalyzed using only data from the first half of each subject's session. In this way, nontarget category became a between-subjects variable; yet the pattern of results was unchanged. For unambiguous targets, mean slopes were 39 and 27 $\mathrm{msec} / \mathrm{item}$, respectively, in within-category and between-category cases. For ambiguous targets, the corresponding values were 18 and $17 \mathrm{msec} / \mathrm{item}$, respectively.

The differences between the present results and the results of Jonides and Gleitman (1972) should be assessed in the context of related studies. As regards the ambiguous target $O$, there have been two previous attempts to replicate the original Jonides and Gleitman (1972) result. Gleitman and Jonides (1976) used the target sets 2, 4, 5, O (called "zero") and A, S, Z, O (called "oh"). Nontargets were drawn from a large set of other letters. In the 4-item displays, digit targets were found faster than letter targets, and in particular "zero" was found faster than "oh." However, in this study no single target was specified before each trial: subjects did not know which (if any) of their four possible targets would be present in any particular display $(T=4)$. Thus, when targets were letters, it was necessary to sort displayed characters into the unfamiliar categories $A, S, Z$, $O$ vs. other letters, irrespective of which (if any) target was actually present. As discussed before, it is not surprising that performance in this condition was always poor.

Three failures to replicate the Jonides and Gleitman (1972) result were described by White (1977, Experiments 5, 6, and 7). A single target "oh," "zero," A, or 4 was specified on each trial. (In Experiment 7, the target 4 was replaced by 2.) Nontargets were drawn from large sets of either digits or letters. There were always six items per display. In Experiments 5 and 6 , the target $O$ was found more quickly among digits than among letters, irrespective of whether it was called "oh" or "zero." However, with the character set used, the mean width of the digits was $.29 \mathrm{deg}$, of the letters, $.36 \mathrm{deg}$, and of the $0, .44 \mathrm{deg}$. The $O$ could not have fit in with the remaining digits as a fully acceptable "zero," and might have been detected on the basis of width alone. Experiment 7 used displays in which each character had a different size or typeface. The target $O$ was found with approximately equal speed among digit and letter nontargets, whether called "oh" or "zero." In this experiment, however, specification of the $\mathrm{O}$ as "oh" or "zero" was varied within-subjects: across trials, the same shape was randomly given one or the other name (cf. also Experiment 5). It was perhaps overoptimistic to suppose that, from one trial to the next, subjects would change their effective categorization of the shape in accord with the name it was given.

Several studies have compared within-category and between-category search with unambiguous targets $(T=1)$. Their results are summarized in Tables 4 and 5. Each study (1) used alphanumeric characters as targets and nontargets, (2) compared within-category and between-category search, and (3) had a single target specified on each trial. Values shown either have been read directly from published tables or have been estimated from published figures after photographic enlargement. Table 4 shows the results of two studies which used large displays through which subjects searched in fixed order (scanning from top to bottom). Values are slopes of the function relating search time to the number of characters preceding the target in the array, that is, the number of nontargets to be searched through before reaching the target. Table 5 shows the results of studies that used small displays (obviating the need for eye movements) with unspecified search order. ${ }^{1}$ Values here are slopes of best-fitting straight lines for functions of RT against display size. The results of Jonides and Gleitman (1972) have been included in Table 5 for comparison.

Several points are made by these data. First, the data show that, for unambiguous targets, slopes can be greater in within-category search than in betweencategory search. This is clear in the results of Brand (1971), Ingling (1972), and Taylor (1978), and confirms the results of Jonides and Gleitman (1972) and the present Experiment 1. The data also show that, as described before, slopes in both withincategory and between-category search are generally positive and variable across studies.

What do the data show concerning the physical resemblance between targets and nontargets? Several

Table 4

Previous Experiments Comparing Within-Category and Between-Category Search With Single Alphanumeric Targets and Large Displays

\begin{tabular}{ccc}
\hline & $\begin{array}{c}\text { Within- } \\
\text { Category } \\
\text { Search }\end{array}$ & $\begin{array}{c}\text { Between- } \\
\text { Category } \\
\text { Search }\end{array}$ \\
\hline Session 1 & \multicolumn{2}{c}{ Brand (1971) } \\
& \multicolumn{3}{c}{55} & 58 \\
Target $=$ B & 77 & 64 \\
Target $=3$ & 83 & 54 \\
Target $=$ Z & 50 & 49 \\
Target $=7$ & 55 & 33 \\
\hline
\end{tabular}

Note-Slopes (in milliseconds/item) for functions of $R T$ against target position. 
Table 5

Previous Experiments Comparing Within-Category and Between-Category Search With Single Alphanumeric Targets and Small Displays

\begin{tabular}{|c|c|c|c|c|}
\hline & \multirow{2}{*}{\multicolumn{2}{|c|}{$\begin{array}{c}\text { Within-Category Search } \\
\text { Target } \\
\end{array}$}} & \multirow{2}{*}{\multicolumn{2}{|c|}{$\frac{\frac{\text { Between-Category Search }}{\text { Target }}}{}$}} \\
\hline & & & & \\
\hline & Present & Absent & Present & Absent \\
\hline & \multicolumn{4}{|c|}{ Jonides \& Gleitman (1972) } \\
\hline \multirow[t]{4}{*}{$\begin{array}{l}\text { Unambiguous Targets } \\
\text { Ambiguous Targets }\end{array}$} & $\begin{array}{l}19 \\
19\end{array}$ & $\begin{array}{l}33 \\
29\end{array}$ & $\begin{array}{l}-1 \\
-2\end{array}$ & $\begin{array}{r}3 \\
-3\end{array}$ \\
\hline & \multicolumn{4}{|c|}{ Taylor (1978), Experiment 3} \\
\hline & 19 & 34 & 3 & 11 \\
\hline & \multicolumn{4}{|c|}{ Corcoran \& Jackson (1977), Experiment 3} \\
\hline \multirow[t]{2}{*}{ Dissimilar Nontargets } & $\begin{array}{l}17 \\
16\end{array}$ & $\begin{array}{l}49 \\
18\end{array}$ & $\begin{array}{r}13 \\
4\end{array}$ & $\begin{array}{l}46 \\
32\end{array}$ \\
\hline & \multicolumn{4}{|c|}{ Egeth et al. (1973), Experiment $1^{*}$} \\
\hline $\begin{array}{l}\text { Target }=A \\
\text { Target }=4\end{array}$ & $\begin{array}{r}14 \\
5\end{array}$ & & $\begin{array}{r}2 \\
11\end{array}$ & \\
\hline
\end{tabular}

Note-Slopes (in milliseconds/item) of best-fitting straight lines for functions of RT against display size. *Values shown are means of values separately estimated for linear and circular displays.

of the studies are relevant. Ingling's (1972) targets were either curved $(B, 3)$ or straight $(Z, 7)$, while her nontargets were largely curved $(2,4,5,6,8,9$ or $A$, C, G, J, P, S). Slopes were considerably greater for the curved targets, an effect somewhat stronger than that of the categorical relationship between target and nontargets. The results of Corcoran and Jackson (1977) were even more striking. Their targets were either curved $(C, 6)$ or straight $(A, 4)$. Nontargets were curved letters, straight letters, or curved digits. Cases in which targets and nontargets were both curved or both straight have been entered in Table 5 in the row labeled "similar nontargets," while cases in which targets were curved and nontargets straight, or vice versa, have been entered in the row labeled "dissimilar nontargets." While a difference in category between targets and nontargets was unimportant in this study, the physical resemblance between the two had a large effect (mean slopes of 31 and 18 msec/item, respectively, for the cases of similar and dissimilar nontargets). Finally, the results of Egeth et al. (1973) may possibly be interpreted in the same way. These authors used the targets $A$ and 4, each with either random letters or random digits as nontargets. For either target, the slopes were less when the nontargets were digits. Possibly, this again reflects the importance of the distinction between straight and curved characters. While A, 4, and more than half the letters of the alphabet are composed entirely of straight lines, nearly all the remaining digits are curved. The importance of this may well have been emphasized by Egeth et al.'s (1973) use of a typeface (Futura demi) with very round curves. ${ }^{2}$ Taken together, the results of these three studies suggest that slopes are heavily influenced by the physical resemblance between target and nontargets, in both within-category and between-category search. In- deed, manipulating this variable can cause the usual category effect to disappear altogether, and perhaps even to reverse.

Thus, when $T=1$, the physical resemblance between target and nontargets can have effects, in both within-category and between-category search, at least as powerful as the category effect itself. This renders increasingly plausible the suggestion that, under these conditions, the category effect reflects no more than uncontrolled variation in physical resemblance. The indication of Experiment 1 that the category effect vanishes when physical resemblance is controlled adds further plausibility. With this in mind, it seems important to know whether the original result of Jonides and Gleitman (1972) can be replicated under the precise conditions of their experiment. In Experiment 2, an attempt was made to follow the procedure of Jonides and Gleitman (1972) in every detail, as regards task, apparatus, and so far as possible subject population.

\section{EXPERIMENT 2}

\section{Method}

Subjects. Forty-eight subjects between the ages of 18 and 26 years (mean $=22.7$ years) were recruited as before. There were 24 of each sex. These were the youngest subjects available from the Applied Psychology Unit panel. Young subjects were chosen to match as far as possible the student subjects of Jonides and Gleitman (1972).

Task. The experiment was run on an Electronic Developments three-field tachistoscope. The two fields used were each set to a luminance of $1.3 \mathrm{log} \mathrm{fL}$ (measured using an SEI Spot Photometer, with a blank white card displayed). Displays were made up of black Chartpak adhesive characters (Alternate Gothic No. 2, 14-point), digits and uppercase letters, presented on white cards. These characters vary somewhat in width: in height, each character subtended a visual angle of $.43 \mathrm{deg}$ at the viewing distance of $50.8 \mathrm{~cm}$. In this character set, the "oh" and "zero" are identical. 
Except during presentation of the stimulus field, a white fixation field with a central black fixation point was displayed throughout. At the start of each trial, a single target character was named aloud to the subject, and a verbal indication given when the apparatus was ready. When prepared, the subject pressed a footswitch, and $\mathbf{4 0 0} \mathrm{msec}$ later the stimulus field was flashed for 150 msec. The stimulus display contained 2,4 , or 6 characters, all different, arranged on the perimeter of an imaginary circle, which was $3.4 \mathrm{deg}$ in diameter and centered on fixation, as in Experiment 1. The named target was present in exactly half the displays. All subjects responded only with the index finger of the preferred hand. Half the subjects (presence responders) pressed the button only if the target was present, while the other half (absence responders) pressed only if the target was absent. In either case, $2 \mathrm{sec}$ were allowed for a response. Thereafter, the experimenter noted any response and its RT, then proceeded with the next trial. Mean time per trial was approximately $10 \mathrm{sec}$

There were 12 possible positions for stimulus characters, corresponding to the clock positions $12.30,1.30$, etc., around the 3.4 deg circle. Positions for each display were chosen at random, with the following constraints. Each display contained at least one pair of diametrically opposite characters, including the target if present. (This time, only precisely opposite characters were counted as such.) Groups of four or more adjacent characters were not allowed.

Deaign. Half the subjects had letter targets $A, Z, O$ (called "oh"), and the other half had digit targets 2, 4, O (called "zero"). Half had letter nontargets and half had digit nontargets, drawn from the same sets as in Experiment 1. As noted before, half the subjects were presence responders and half were absence responders. Orthogonal variation of these three between-subjects factors resulted in eight groups of six subjects each. Assignment of subjects to groups was random, except that approximately half the subjects in each group were of each sex.

Each subject served in a single session of about $\mathbf{4 0} \mathrm{min}$. A practice block of 18 trials was followed by an experimental block of 108 trials, with a short rest in the middle of the latter. When an error was made, a dummy trial from which data were not collected was given immediately thereafter. The error trial was then rerun later in the session.

Blocks were always mixed. Within the 108 experimental trials, the following factors were varied orthogonally: 3 (target identities) $\times 3$ (display sizes) $\times 2$ (target present vs. absent) $\times 6$ (target positions A to F: a dummy variable for target-absent displays ${ }^{3}$ ). The first three factors were varied orthogonally, not only in the block as a whole, but also in each successive subblock of 36 trials. These three factors were also varied orthogonally in the practice block of 18 trials. Otherwise, the sequence of trials was random, although fixed across subjects.

One hundred and thirty-six cards were made up for each combination of target and nontarget categories, plus a few extras for the dummy trials immediately following errors. Thus, no card was repeated during a session, except when error trials were rerun. Nontargets for each card were chosen at random and without replacement from the appropriate set.

Instructions. As before, target and nontarget categories were clearly described at the start of the session. Subjects were asked to respond as fast as possible but without making mistakes.

\section{Results}

Reaction times. Functions of RT against display size for the unambiguous targets $A, Z, 2$, and 4 are shown on the left half of Figure 3. Slopes and inter-

\section{UNAMBIGUOUS TARGETS}
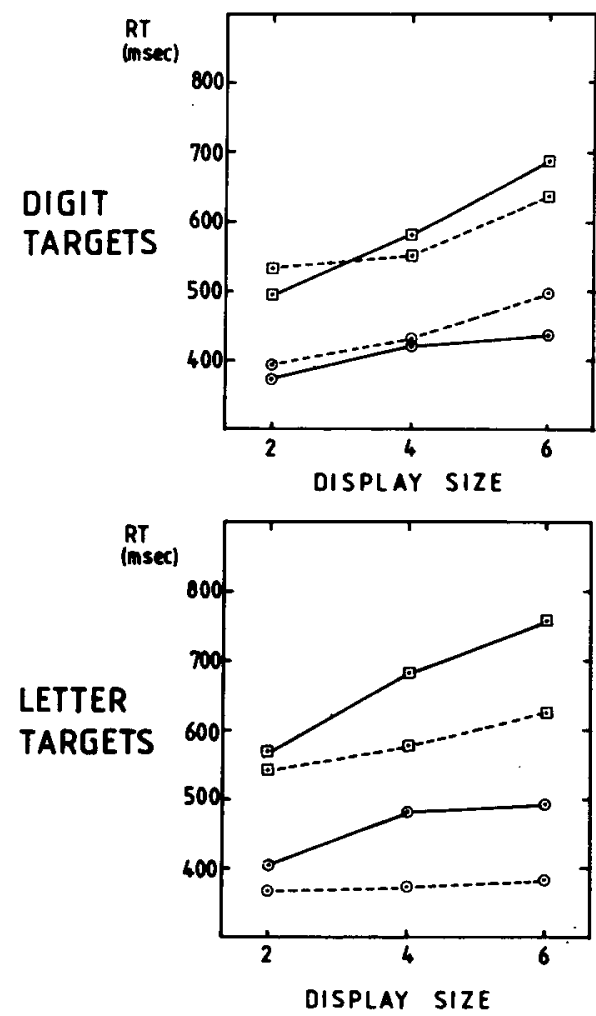

\section{AMBIGUOUS TARGETS}
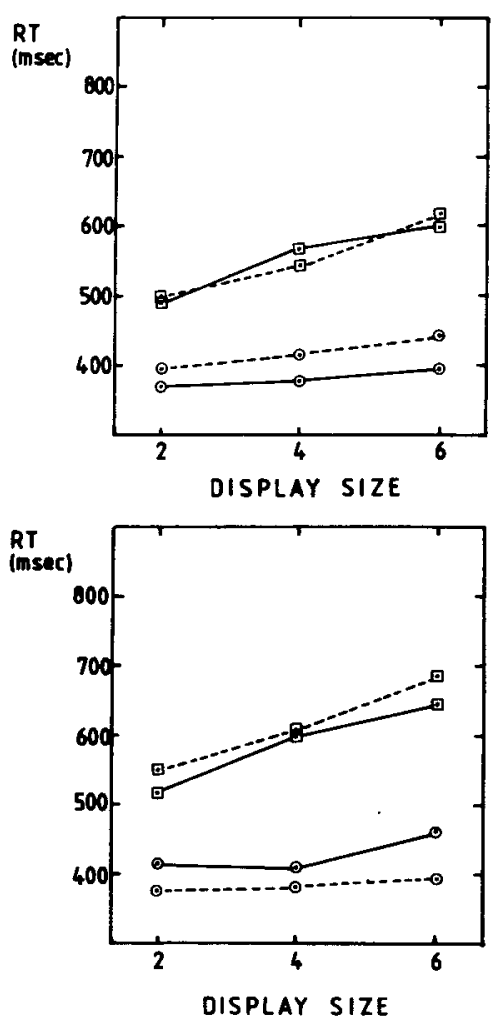

Figure 3. Experiment 2: Functions of RT againat display size. between category search; $O$, target present; $\square$, target absent. 
Table 6

Slopes (in Milliseconds/Item) and Intercepts (in Milliseconds) of Best-Fitting Straight Lines for Functions of RT Against Display Size in Experiment 2

\begin{tabular}{|c|c|c|c|c|c|}
\hline & & \multirow{2}{*}{\multicolumn{2}{|c|}{$\frac{\text { Within-Category Search }}{\text { Target }}$}} & \multirow{2}{*}{\multicolumn{2}{|c|}{$\frac{\text { Between-Category Search }}{\text { Target }}$}} \\
\hline & & & & & \\
\hline & & Present & Absent & Present & Absent \\
\hline & & \multicolumn{4}{|c|}{ Unambiguous Targets } \\
\hline Digit Targets & $\begin{array}{l}\text { Slope } \\
\text { Intercept }\end{array}$ & $\begin{array}{r}16 \\
348\end{array}$ & $\begin{array}{r}48 \\
395\end{array}$ & $\begin{array}{r}26 \\
337\end{array}$ & $\begin{array}{r}26 \\
469\end{array}$ \\
\hline \multirow[t]{2}{*}{ Letter Targets } & $\begin{array}{l}\text { Slope } \\
\text { Intercept }\end{array}$ & $\begin{array}{r}22 \\
372\end{array}$ & $\begin{array}{r}47 \\
481\end{array}$ & $\begin{array}{r}4 \\
359\end{array}$ & $\begin{array}{r}22 \\
496\end{array}$ \\
\hline & & \multicolumn{4}{|c|}{ Ambiguous Targets } \\
\hline Digit Targets & $\begin{array}{l}\text { Slope } \\
\text { Intercept }\end{array}$ & $\begin{array}{r}6 \\
357\end{array}$ & $\begin{array}{r}27 \\
443\end{array}$ & $\begin{array}{r}12 \\
370\end{array}$ & $\begin{array}{r}29 \\
435\end{array}$ \\
\hline Letter Targets & $\begin{array}{l}\text { Slope } \\
\text { Intercept }\end{array}$ & $\begin{array}{r}12 \\
379\end{array}$ & $\begin{array}{r}32 \\
460\end{array}$ & $\begin{array}{r}5 \\
364\end{array}$ & $\begin{array}{r}34 \\
481\end{array}$ \\
\hline
\end{tabular}

cepts of the best-fitting straight lines for these functions are shown in the upper half of Table 6.

The most important results of Experiment 1, concerning the comparison of within-category and between-subjects factors and display size $(2,4,6)$ as a within-subjects factor. The results described above average of $4 \mathrm{msec} /$ item for target-present displays and $23.5 \mathrm{msec} /$ item for target-absent displays. Again, however, all slopes were positive, in contrast to the results of Jonides and Gleitman (1972).

The data were examined by analysis of variance, with search type (within-category vs. betweencategory), target presence (presence vs. absence responders), and target category (digits vs. letters) as between-subjects factors and display size $(2,4,6)$ as a within-subjects factor. The result described above were reflected in significant effects of display size $[F(2,80)=41.1, p<.001]$ and search type $x$ display size $[F(2,80)=3.8, p<.05]$. The only other significant effects were those of target presence $[F(1,40)$ $=43.9, p<.001]$ and target presence $x$ display size $[F(2,80)=5.6, p<.01]$, reflecting, as before, the usual differences between target-present and targetabsent RTs.

Corresponding data for the ambiguous target $O$ are shown in the right half of Figure 3 and the bottom half of Table 6. Again, the results of Experiment 1 were replicated, but with increased clarity. There was no hint of any difference between withincategory and between-category search. In the corresponding analysis of variance, the only significant effects were those of target presence $[F(1,40)=$ $37.9, \mathrm{p}<.001]$, display size $[\mathrm{F}(2,80)=23.0, \mathrm{p}<$ $.001]$, and target presence $x$ display size $[F(2,80)=$ $7.4, \mathrm{p}<.01$ ]

To assess the power of the experiment, data for ambiguous targets were subjected to a further analysis in which best-fitting straight lines were fit to functions of RT against display size for each subject. Slopes were entered into a two-way analysis of variance with search type and target presence as between- subjects factors. Collapsing across target presence, mean slopes were 19.0 and $19.8 \mathrm{msec} / \mathrm{item}$, respectively, in within-category and between-category search. The standard error of each mean was 4.7 $\mathrm{msec} / \mathrm{item}$. The difference in the means is -0.8 $\mathrm{msec} / \mathrm{item}$, with a standard error of $6.7 \mathrm{msec} / \mathrm{item}$.

One possibility remains to account for the discrepancies between the present results and those of Jonides and Gleitman (1972). Of the 48 subjects tested in the present case, 23 had either obtained or were working towards an undergraduate degree, as opposed to presumably all 48 in the earlier experiment. Some related difference in the subjects themselves could possibly have been responsible for the difference in results. A further analysis of the present data discounted this possibility. For the subjects who had or were working towards a degree, mean slopes in within-category and between-category search were 32 and $24 \mathrm{msec} /$ item, respectively, for unambiguous targets and 21 and $19 \mathrm{msec} / \mathrm{item}$, respectively, for ambiguous targets. For the remaining subjects (less one whose educational history was unknown), corresponding values were 34 and $14 \mathrm{msec} / \mathrm{item}$, respectively, for unambiguous targets and 18 and 24 msec/item, respectively, for ambiguous targets. There is no suggestion that subjects with higher education are more likely to produce results like those of Jonides and Gleitman (1972).

Errors. Mean error rates, averaged across the variable of target category (digits vs. letters), are shown in Table 7. The overall tendency was for error rates to increase with increasing display size. For unambiguous targets, this tendency was stronger in withincategory search than in between-category search. For ambiguous targets it was not.

\section{Discussion}

The results of Experiment 1 were replicated with increased clarity in Experiment 2. Differences in slope between within-category and between-category search appeared only for unambiguous targets. All 
Table 7

Error Proportions in Experiment 2

\begin{tabular}{|c|c|c|c|c|c|c|c|}
\hline & & \multirow{2}{*}{\multicolumn{3}{|c|}{$\frac{\text { Within-Category Search }}{\text { Display Size (Characters) }}$}} & \multirow{2}{*}{\multicolumn{3}{|c|}{$\frac{\text { Between-Category Search }}{\text { Display Size (Characters) }}$}} \\
\hline & & & & & & & \\
\hline & & 2 & 4 & 6 & 2 & 4 & 6 \\
\hline & & \multicolumn{6}{|c|}{ Unambiguous Targets } \\
\hline Presence Responders & $\begin{array}{l}\text { Target Present } \\
\text { Target Absent }\end{array}$ & $\begin{array}{l}.000 \\
.006\end{array}$ & $\begin{array}{l}.000 \\
.029\end{array}$ & $\begin{array}{l}.052 \\
.054\end{array}$ & $\begin{array}{l}.006 \\
.012\end{array}$ & $\begin{array}{l}.006 \\
.012\end{array}$ & $\begin{array}{l}.012 \\
.024\end{array}$ \\
\hline \multirow[t]{2}{*}{ Absence Responders } & $\begin{array}{l}\text { Target Present } \\
\text { Target Absent }\end{array}$ & $\begin{array}{l}.028 \\
.000\end{array}$ & $\begin{array}{l}.024 \\
.006\end{array}$ & $\begin{array}{l}.055 \\
.042\end{array}$ & $\begin{array}{l}.030 \\
.006\end{array}$ & $\begin{array}{l}.024 \\
.012\end{array}$ & $\begin{array}{l}.024 \\
.022\end{array}$ \\
\hline & & \multicolumn{6}{|c|}{ Ambiguous Targets } \\
\hline Presence Responders & $\begin{array}{l}\text { Target Present } \\
\text { Target Absent }\end{array}$ & $\begin{array}{l}.012 \\
.012\end{array}$ & $\begin{array}{l}.024 \\
.021\end{array}$ & $\begin{array}{l}.074 \\
.045\end{array}$ & $\begin{array}{l}.000 \\
.021\end{array}$ & $\begin{array}{l}.000 \\
.012\end{array}$ & $\begin{array}{l}.000 \\
.000\end{array}$ \\
\hline Absence Responders & $\begin{array}{l}\text { Target Present } \\
\text { Target Absent }\end{array}$ & $\begin{array}{l}.060 \\
.000\end{array}$ & $\begin{array}{l}.012 \\
.000\end{array}$ & $\begin{array}{l}.000 \\
.036\end{array}$ & $\begin{array}{l}.012 \\
.000\end{array}$ & $\begin{array}{l}.000 \\
.033\end{array}$ & $\begin{array}{l}.024 \\
.077\end{array}$ \\
\hline
\end{tabular}

slopes were positive, and variable in both withincategory and between-category cases. Of course, it remains possible that some unknown variable accounts for the discrepancies between the results of Jonides and Gleitman (1972) and those obtained here. Perhaps a stronger possibility, however, is that the original results simply cannot be replicated.

The results of Experiment 2 add further evidence that, when $T=1$, the category effect vanishes if the physical resemblance between target and nontargets is controlled. There are two reasons for caution over this result. The first reason is the problem of failure to reject the null hypothesis. A small category effect even for the target $O$ could have gone undetected in these experiments. The second reason is the problem of ensuring an appropriate mental set. Although every effort was made to ensure that subjects categorized the stimulus $O$ as intended by the experimenter, one cannot be certain that they always did so. (On the other hand, it seems unlikely that their failure in this respect could have been so complete as to abolish the category effect altogther.) Thus, while it does seem that the large category effect for the target $O$, reported by Jonides and Gleitman (1972), is not replicable, at this stage one should conclude only with caution that the category effects that are seen with unambiguous targets are due entirely to uncontrolled variation in target-nontarget resemblance.

In a second respect, the present data allow stronger conclusions. Even under the experimental conditions of Jonides and Gleitman (1972), slopes are positive and variable in both within-category and betweencategory search. This conclusion is in accord with the body of previous data summarized in Tables 4 and 5 . Doubtless many factors contribute to variability in absolute slopes, including individual differences (which in my experience are very large), the degree of practice (Egeth, Jonides, \& Wall, 1972), legibility of character sets, packing of displays, exposure duration (Egeth et al., 1973), and so on. I even have pilot data suggesting that slopes are greater when the left hand is used to respond to targets and the right to nontargets than with the reverse arrangement. Thus, it is a mistake to try to differentiate between-category and within-category cases in terms of the range of absolute slopes seen across experiments. Certainly, the data do not suggest that between-category search is parallel whereas within-category search is serial.

This paper has been concerned only with the case in which $T=1$. In between-category search, increasing $\mathrm{T}$ above 1 usually has little effect (e.g., Egeth et al., 1972; Schneider \& Shiffrin, 1977). Across studies, for the case of $T>1$, one sees a range of positive slopes comparable to that seen for $T=1$ (Egeth et al., 1972, 1973; Gleitman \& Jonides, 1976, 1978; Jonides \& Gleitman, 1976; Schneider \& Shiffrin, 1977). Doubtless, as discussed before, this minimal effect of variation in $\mathrm{T}$ reflects the fact that, whatever the value of $T$ in between-category search, the classification separating targets from nontargets is always well learned. The situation is very different in within-category search. As T increases, performance rapidly declines, producing a rapidly increasing category effect (e.g., Schneider \& Shiffrin, 1977). Again, this undoubtedly reflects the requirement for illlearned classifications of increasing complexity.

The conclusion is that the category effect in visual search has two parts. With $\mathrm{T}>1$, it reflects the difference between well-learned and ill-learned classifications. With $\mathrm{T}=1$, it may well reflect no more than uncontrolled variation in the physical resemblance between target and nontargets.

A final set of evidence is relevant to this conclusion. Using words rather than alphanumeric characters as their stimuli, Karlin and Bower (1976) compared within-category and between-category cases with categories defined semantically (colors, trees). When words are the stimuli, it is implausible that items from the same category are more similar physically than items from different categories. Correspondingly, no category effect was obtained with $T=1$. But, as $T$ was increased, calling for ill-learned 
classifications in the within-category case, a category effect increasingly appeared, as the present account would predict.

\section{REFERENCES}

Brand, J. Classification without identification in visual search. Quarterly Journal of Experimental Psychology, 1971, 23, 178-186.

Corcoran, D. W. J., \& J Ackson, A. Basic processes and strategies in visual search. In S. Dornic (Ed.), Attention and performance VI. Hillsdale, N.J: Erlbaum, 1977.

Duncan, J. The locus of interference in the perception of simultaneous stimuli. Psychological Review, 1980, 87, 272-300.

Egeth, H., Atkinson, J., Gilmore, G., \& Marcus, N. Factors affecting processing mode in visual search. Perception \& Psychophysics, 1973, 13, 394-402.

Eazth, H., Jonides, J., \& WAll, S. Parallel processing of multielement displays. Cognitive Psychology, 1972, 3, 674-698.

Eriksen, C. W., \& Spencer, T. Rate of information processing in visual perception: Some results and methodological considerations. Journal of Experimental Psychology Monograph, 1969, $79(2$, Pt. 2).

Gleitman, H., \& Jonides, J. The cost of categorization in visual search: Incomplete processing of targets and field items. Perception \& Psychophysics, 1976, 20, 281-288.

Gleitman, H., \& Jonides, J. The effect of set on categorization in visual search. Perception \& Psychophysics, 1978, 24, 361-368.

Ingling, N. W. Categorization: A mechanism for rapid information processing. Journal of Experimental Psychology, 1972, 94, 239-243.

Jonides, J., \& Gleituan, H. A conceptual category effect in visual search: $O$ as letter or as digit. Perception \& Psychophysics, 1972, 12, 457-460.

Jonides, J., \& GleitunN, H. The benefit of categorization in visual search: Target location without identification. Perception \& Psychophysics, 1976, 20, 289-298.

KARLIN, M. B., \& Bower, G. J. Semantic category effects in visual word search. Perception \& Psychophysics, 1976, 19, 417-424.
Ne ISSER, U. Decision-time without reaction-time: Experiments in visual scanning. American Journal of Psychology, 1963, 76, 376-385.

Schneider, W., \& Shiffrin, R. M. Controlled and automatic human information processing: I. Detection, search, and attention. Psychological Review, 1977, 84, 1-66.

Shirfrin, R. M., \& Schneider, W. Controlled and automatic human information processing: II. Perceptual learning, automatic attending, and a general theory. Psychological Review, 1977, 84, 127-190.

TAYLOR, D. A. Identification and categorization of letters and digits. Journal of Experimental Psychology: Human Perception and Performance, 1978, 4, 423-439.

WHITE, M. J. Identification and categorization in visual search. Memory \& Cognition, 1977, 5, 648-657.

\section{NOTES}

1. A study by Schneider and Shiffrin (1977, Experiment 2) has been omitted from Table S. Although it compared within-category and between-category search with single, specified alphanumeric targets, the two search conditions differed also in a second variable termed "consistency of mapping." Thus, for a single subject, within-category targets were used elsewhere in the experiment as nontargets, while between-category targets were not. Mean slopes were $12 \mathrm{msec} /$ item in within-category (varied mapping) search, and $0 \mathrm{msec} / \mathrm{item}$ in between-category (consistent mapping) search.

2. The target 4 is not easier to find among digits than among letters with all typefaces. In the present two experiments, the mean slope for this target alone was about $9 \mathrm{msec} / \mathrm{item}$ less in betweencategory search than in within-category search. Note, however, that this value is about half the mean slope difference $(16 \mathrm{msec} /$ item) for unambiguous targets as a whole.

3. For this purpose, positions were grouped into pairs as in Experiment 1. Pair A corresponded to positions 12.30 and 1.30, pair $B$ to 2.30 and 3.30, and so on.

(Manuscript received February 7, 1983; revision accepted for publication May 6, 1983.) 